\title{
Binding of Quinine- and Quinidine-dependent Drug Antibodies to Platelets Is Mediated by the Fab Domain of the Immunoglobulin $G$ and Is Not Fc Dependent
}

\author{
Mark E. Smith, Diane M. Reid, Charlie E. Jones, James V. Jordan, Carol A. Kautz, and N. Raphael Shulman
}

Clinical Hematology Branch, National Institute of Diabetes, Digestive and Kidney Diseases,

National Institutes of Health, Bethesda, Maryland 20892

\begin{abstract}
The antibody domain controlling reactions between platelet membranes and drug-dependent (dd) antibodies from patients with thrombocytopenia induced by cinchona alkaloids was studied using $F\left(a b^{\prime}\right)_{2}$, Fab, and Fc fragments made from purified ddIgG. By direct binding radioimmunoassay (RIA) measurements, 20,000 to 50,000 antibody molecules bound per platelet equivalent of purified platelet membranes at apparent saturation with three different antibodies. $F\left(\mathbf{a b}^{\prime}\right)_{2}$ and $F a b$ fragments bound to platelet membranes drug dependently but Fc fragments did not. The ability of dd-IgG fragments to compete with intact IgG was quantitatively measured by RIA and by complement fixation. $F\left(a b^{\prime}\right)_{2}$ and Fab competed with intact IgG at an 8:1 and > 50:1 molar ratio, respectively, in RIA, and at a 1.6-3:1 and 44-75:1 ratio, respectively, by complement fixation assays. Fc did not compete with IgG in either assay. We conclude that the Fab domain supports attachment of dd antibody to the platelet surface.
\end{abstract}

\section{ntroduction}

Drug-induced antibodies that cause thrombocytopenia attach to platelet membranes in a high affinity reaction only when the sensitizing drug or one of its analogues is present in solution (14). In vitro binding of the antibody to platelet membranes has been measured over drug concentrations of $10^{-7}$ to $>10^{-2} \mathrm{M}$ (2-4), while in vivo binding, as evidenced by decreases in circulating platelets, has been observed at drug concentrations as low as $10^{-9} \mathrm{M}(5,6)$. The highest concentrations of drug used in antibody binding experiments, $10^{-3}-10^{-1.8} \mathrm{M}$, supported maximal attachment of antibody to platelets even when antibody concentrations were in the range of $10^{-8}-10^{-9} \mathrm{M}(3,4)$ and cell membrane receptors were in the range of $10^{-8} \mathrm{M}$. Thus, under conditions of a fixed ratio of antibody concentration to platelet concentration, antibody binding to platelets in vitro is saturable with increasing concentrations of free drug and remains so as drug is increased to at least $10^{5}$-fold greater than the concentration of either antibody or platelet binding sites.

\footnotetext{
A preliminary report of this work was presented at the 26th Annual Meeting of the American Society for Hematology, December 1984.

Address reprint requests to Dr. Shulman, CHB:NIDDK, NIH, Bldg. 10, Rm. 8C101, 9000 Rockville Pike, Bethesda, MD 20892. Dr. Smith's current address is Cancer Research Center, Columbia, MO 65203, and Dr. Jordan's current address is Christ Hospital, Chicago, IL 60453. Received for publication 11 June 1986.
}

The Journal of Clinical Investigation, Inc.

Volume 79, March 1987, 912-917
Since haptenic inhibition of antibody attachment to platelets does not occur, the assumption that simple haptenic conjugation of the drug or a metabolite with the platelet surface creates a site for antibody attachment cannot be defended. Moreover, platelets exposed to drug and washed once in the absence of drug-dependent (dd) ${ }^{1}$ antibody are incapable of supporting antibody attachment $(3,4)$. To be consistent with these observations, it was proposed that antibody binds drug, resulting in an immune complex that can be adsorbed by platelet membrane binding sites $(2,3)$. Although antigen-antibody complexes generally are considered to be adsorbed by cell membrane Fc receptors through the activated Fc domain of the antibody, the platelet surface component that interacts with drug antibodies has been demonstrated to be the glycoprotein I complex, which has a reduced apparent molecular weight $\left(M_{\mathrm{r}}\right)$ of $150,000(7)$. This receptor differs significantly from the platelet Fc receptors thus far described which, when reduced, have $M_{r} s$ of 40,000 (8) and 50,000 (9). Moreover, if Fc receptors were involved, drug antibodies would be expected to bind to more than one cell type, but anti-platelet drug antibodies are exclusively specific for platelets $(1,2,6,10)$. Additionally, drug antibodies that react with granulocytes or erythrocytes show no binding to platelets $(6,10)$.

These observations indicate that the cell membrane binding site for drug antibodies contributes some of the specificity to the overall interaction. Since adsorption of a drug-antibody complex via the Fc domain does not appear to occur, one might expect dd antibodies to attach via the Fab domain. However, two groups of investigators have described unsuccessful attempts to demonstrate drug-mediated binding of $F\left(a b^{\prime}\right)_{2}$ fragments prepared from dd- $\operatorname{IgG}(11,12)$. Nevertheless, there is a possibility that the anti-IgG used in these experiments may not have reacted with $\mathrm{F}\left(\mathrm{ab}^{\prime}\right)_{2}$; experiments to document the reactivity of the anti-IgG used were not mentioned. On the other hand, Staphylococcus aureus protein A has been used successfully to detect dd-IgG on platelet surfaces $(10,12-14)$; hence the Fc domain of the ddIgG is accessible after binding. Thus, either the Fab domain is primarily involved in binding dd-IgG to the platelet surface or Fc-mediated binding does not interfere with protein A binding to the Fc region. That the latter may be possible is evident from observations on Fc receptor binding of IgG complexed to protein A (15).

We have generated data indicating that the Fab domain of the dd-IgG rather than the Fc domain supports attachment of the antibodies to cell membranes. The high affinity antibodydrug-platelet ternary complex appears to involve cooperative interaction among the three reactants, in that the affinity between any two of the reactants in the absence of the third is too low to be measured by techniques that have been applied to date.

1. Abbreviation used in this paper: dd, drug-dependent. 


\section{Methods}

Patients. The antibodies studied were from three patients who developed severe thrombocytopenia while taking either quinine or quinidine therapeutically. dd antibody binding in each serum was initially quantitated by complement fixation assays as reported previously (2).

Production of purified IgG and fragments. $10 \mathrm{ml}$ of whole serum containing dd antibody was dialyzed against $0.020 \mathrm{M}$ potassium phosphate, pH 8.2, and applied to a $1.5 \times 45-\mathrm{cm}$ column of DEAE-Affigel blue (Bio-Rad Laboratories, Richmond, CA) equilibrated with the same buffer. The protein peak not retained by this column was composed of $\sim 90 \%$ IgG and $10 \%$ transferrin based upon analysis of the pooled material by silver-stained sodium dodecyl sulfate-polyacrylamide gel electrophoresis (SDS-PAGE) $(16,17)$. Fab fragments were prepared from this partially purified IgG by papain digestion (18) and gel filtration on Sephacryl S-300 $(2.5 \times 95 \mathrm{~cm})$. Eluate fractions containing both Fab and $\mathrm{Fc}$ were applied sequentially to a protein A-Sepharose column then an anti-Fc-Sepharose column to remove the $\mathrm{Fc}$ fragments, yielding purified Fab fragment containing $<2 \%$ contaminants. The bound $\mathrm{Fc}$ fragments were eluted from these columns with $1.0 \mathrm{M}$ acetic acid, pH 3.0. The fractions were immediately neutralized by the addition of sodium hydroxide and concentrated by ultrafiltration over an Amicon YM-10 ultrafiltration membrane. The $F\left(a b^{\prime}\right)_{2}$ fragment was prepared by pepsin digestion of the partially purified IgG (19). The crude digestion mixture was also applied to a Sephacryl S-300 gel filtration column as described above and subsequently residual IgG and degraded Fc fragments were removed by adsorption to a protein A-Sepharose column. The purity of all these fragments was determined by analytical SDS-PAGE (e.g., Fig. 7).

Platelet membrane preparation. Platelets were obtained from normal donors by platelet apheresis using citrate anticoagulant. EDTA was added to the platelet-rich plasma to a final concentration of $5.0 \mathrm{mM}$ and platelets were washed three times in phosphate-buffered saline (PBS), $5.0 \mathrm{mM}$ EDTA. To prepare membranes, glycerol-loaded platelets were lysed by hyptonic shock and the membrane fragments were separated from intact platelets, cellular debris, and organelles by centrifugation through a discontinuous sucrose density gradient (20). The membrane preparation sedimented to the interface between the $0.25 \mathrm{M}$ and $27 \%$ sucrose solutions. The material that sedimented through the $27 \%$ sucrose cushion was resuspended in $0.25 \mathrm{M}$ sucrose and subjected to a second differential centrifugation. This procedure resulted in a greater recovery of the platelet drug-antibody receptor as has been previously described (7). Protein concentration in platelet membrane suspensions was determined using fluorescence measurements after derivitization with o-phthalaldehyde (21). Membranes were washed and resuspended in PBS and stored at $-70^{\circ} \mathrm{C}$. Each batch of platelet membranes was evaluated using radioimmunoassay (RIA) for $\mathrm{Pl}^{\mathrm{A}}$ antigen (22). Specifically, glycoprotein IIIa was purified by differential detergent extraction (23) and gel filtration on Sephacryl S-300 (24) and radiolabeled using a chloramine-T method (25). The immunoassay consisted of mixing this radiolabeled antigen with anti-PI ${ }^{\wedge 1}$ at molar equivalence and precipitating the resulting antigen-antibody complexes with formalin-fixed $S$. aureus to obtain the maximum value for percent binding in Fig. 1. Curves were then obtained using varying amounts of either intact platelets or platelet membranes to compete with the labeled glycoprotein for anti-PI ${ }^{\wedge 1}$, as shown in Fig. 1. By comparing the number of intact platelets with the amount of purified platelet membranes required to inhibit binding by $50 \%$, a specific amount of platelet membrane protein could be converted to an equivalence of whole platelets based upon $\mathrm{Pl}^{\wedge 1}$ antigen content.

dd binding to platelet membranes. All fragments of each antibody were assayed using a single preparation of platelet membranes to minimize the variation in receptor concentration that may arise from comparisons among individual platelet preparations. Membrane fragments were washed once and diluted in PBS, $0.5 \%$ bovine serum albumin (BSA), and $1.0 \mathrm{mM}$ EDTA. The amount of platelet membrane protein equivalent to $1.3 \times 10^{7}$ platelets $(\sim 10 \mu \mathrm{g}$ of protein) was incubated with purified IgG or the purified IgG fragments, with or without the addition of appropriate drug ( $1.0 \mathrm{mM}$ final concentration) in a total volume of 0.15

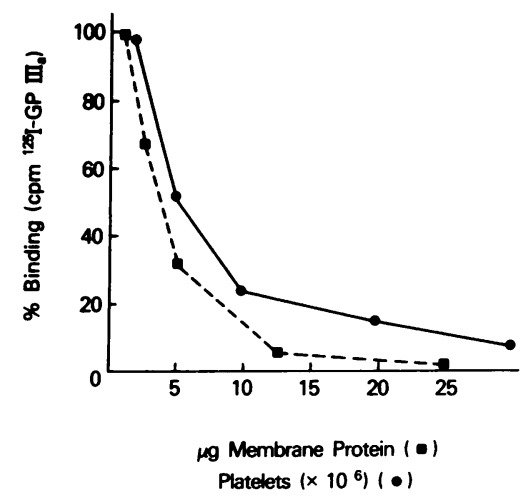

Figure 1. Standardization of purified platelet membranes. As described in Methods, purified platelet membranes and the intact platelets from which they were prepared were compared with respect to their ability to displace ${ }^{125}$ I-labeled GPIIIa from anti-PlA1. The number of platelets or the amount of membrane protein capable of producing $50 \%$ competitive inhibition was taken as the equivalence point, allowing calibration of the platelet membrane preparation. 10 $\mu \mathrm{g}$ of purified platelet membrane was equivalent to $\sim 1.3 \times 10^{7}$ platelets.

$\mathrm{ml}$. This mixture was incubated for $\mathbf{3 0} \mathrm{min}$ at room temperature, centrifuged at $12,000 \mathrm{~g}$ for $5 \mathrm{~min}$ in a Beckman model 12 microfuge, and the pellet was washed three times in saline with or without the appropriate drug. An acid eluate was prepared from the final washed pellet by resuspension in $266 \mu \mathrm{l}$ of PBS, $0.5 \%$ BSA, plus $133 \mu \mathrm{l}$ of $10 \mathrm{mM}$ phosphoric acid, to give a final $\mathrm{pH}$ of 3.1. This mixture was incubated at room temperature for $10 \mathrm{~min}$ and again centrifuged at $12,000 \mathrm{~g}$ for $10 \mathrm{~min}$, after which $52 \mu \mathrm{l}$ of $2.5 \mathrm{M}$ Tris, $\mathrm{pH}$ 10.0, was added to a 332- $\mu$ l aliquot of the supernatant to bring the $\mathrm{pH}$ to $\sim 7.0$.

A "sandwich" RIA was used to measure eluted IgG (26). Various dilutions of the eluates in $40-\mu \mathrm{l}$ aliquots were added to $100 \mu \mathrm{l}$ of RIA buffer ( $10 \mathrm{mM}$ Tris $\mathrm{HCl}, 0.5 \% \mathrm{BSA}, \mathrm{pH} 8.3$ ) and then loaded onto wells of polystyrene microtiter plates that had been precoated with anti-human IgG (affinity-purified goat anti-human IgG, heavy chain-specific; Kirkegaard \& Perry, Gaithersburg, MD). After incubation for 2-18 h at room temperature, the plates were washed with RIA buffer, and a radioiodinated second antibody (antihuman IgG from the same lot as the material with which the plate was originally coated) diluted in RIA buffer to contain $50,000-100,000 \mathrm{cpm} / 100 \mu \mathrm{l}$ was added to each well. This labeled antibody was allowed to bind for $2 \mathrm{~h}$ at room temperature. The plates were then washed three times, and individual wells were cut out and counted in a gamma counter. The quantitative results were determined from standard curves on control IgG, $F\left(a^{\prime}\right)_{2}$, Fab, or Fc that were run with each determination. A typical set of standard curves is shown in Fig. 2. The raw data was analyzed by a modified logit transformation, where each curve was subjected to linear regression analysis. Standard curves spanning the range of $0.05-125 \mathrm{ng}$ of IgG or its fragments were used to quantitate the total acid eluted immunoreactive material.

Quantitative complement fixation. Briefly, the dd-IgG was incubated with $8 \times 10^{7}$ platelets in the presence of $10 \mathrm{U}$ of guinea pig complement with or without appropriate drug. After $30 \mathrm{~min}$ of incubation at $37^{\circ} \mathrm{C}$ the reaction was stopped, an aliquot of the suspension removed, and the complement activity remaining in the aliquot was quantitated using an indicator system of hemolysin-sensitized sheep red blood cells. The assay procedure was identical to that described previously (27) for direct determination of IgG binding as well as for evaluation of competitive binding of non-complement-fixing IgG allo-antibodies in the presence of complement-fixing antibodies of the same specificity.

When competitive experiments were performed, the order of addition of reagents to the reaction mixture was as follows: veronal-buffered saline; platelets; IgG; IgG fragments $\left[\mathrm{F}\left(\mathrm{ab}^{\prime}\right)_{2}, \mathrm{Fab}\right.$, or $\left.\mathrm{Fc}\right]$; guinea pig complement; and drug.

Preparation of purified dd-IgG. A 50-ml sample of whole serum containing a cross-reacting (quinidine and quinine) dd-IgG was incubated with $96 \mathrm{mg}$ of purified platelet membrane protein, which was equivalent to $\sim 1.3 \times 10^{11}$ platelets, for $18 \mathrm{~h}$ at room temperature in $1.0 \mathrm{mM}$ quinidine. The supernatant (adsorbed serum) of this incubation contained $\sim 5 \%$ of the initial concentration of antibody. The membranes were 


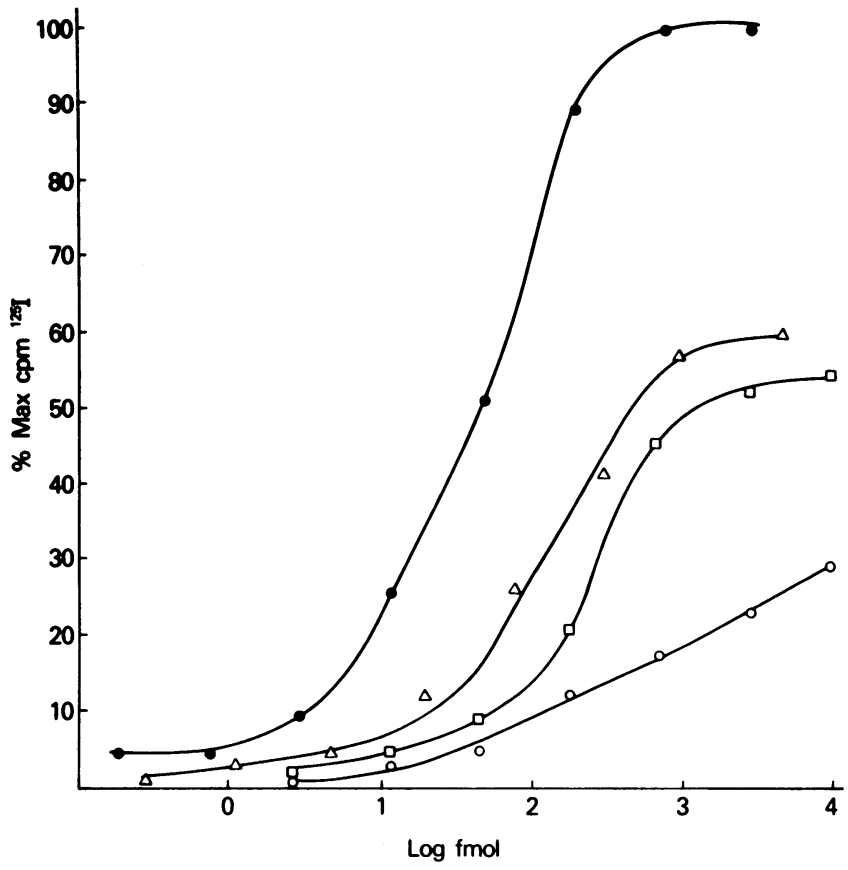

Figure 2. Standard curves for quantitation of IgG and IgG fragments in the solid-phase RIA. Known amounts of IgG (solid circles), $\mathbf{F}\left(\mathrm{ab}^{\prime}\right)_{2}$ (triangles), Fab (squares), and Fc (open circles) fragments were added to immobilized affinity-purified polyclonal anti-human IgG coated on microtiter plates and then exposed to radiolabeled anti-human IgG. Values for the fragments are normalized and compared with the maximum binding of $\operatorname{IgG}$ under identical assay conditions.

washed three times in PBS containing 0.5\% BSA and $1.0 \mathrm{mM}$ quinidine. The washed membranes were resuspended in $2.0 \mathrm{ml}$ PBS, $0.5 \%$ BSA. The $\mathrm{pH}$ was then adjusted to 2.8 with dilute phosphoric acid, and the membranes, after incubation for $10 \mathrm{~min}$ in these acid conditions, were removed by centrifugation. The $\mathrm{pH}$ of the supernatant was immediately adjusted to 7.0 with dilute $\mathrm{NaOH}$. This acid eluate contained $1.4 \times 10^{-8}$ mol of IgG by RIA, of which $95 \%$ was dd. This percentage was determined by quantitating the maximum amount of IgG bound when an aliquot of eluate was exposed to an excess of platelet membrane in the presence of $1.0 \mathrm{mM}$ quinidine.

For further purification, the eluate was then applied to a protein ASepharose column equilibrated in PBS, and the adsorbed dd-IgG was eluted in $1.0 \mathrm{M}$ acetic acid, $\mathrm{pH} 2.8$, pooled, and neutralized. Aliquots of $10 \mu \mathrm{g} \mathrm{dd-IgG}$ were radioiodinated with ${ }^{125} \mathrm{I}$ using chloramine-T (25).

Acid elution and electrophoresis of platelet-bound radiolabeled $F\left(a b^{\prime}\right)_{2}$. $\mathrm{F}\left(\mathrm{ab}^{\prime}\right)_{2}$ was prepared by pepsin digestion of IgG separated from serum of patient III and labeled with ${ }^{125} \mathrm{I}$ by the chloramine-T method (25). $1.5 \times 10^{9}$ platelets were mixed with sufficient ${ }^{125} \mathrm{I}-\mathrm{F}\left(\mathrm{ab}^{\prime}\right)_{2}$ to saturate binding sites, assuming $\mathrm{F}\left(\mathrm{ab}^{\prime}\right)_{2}$ attached to platelets in the same quantities as dd-IgG. Quinidine gluconate was added to achieve a final drug concentration of $1 \mathrm{mM}$. Drug was omitted in the control mixture. After incubation at room temperature for $24 \mathrm{~h}$, platelets were pelleted and supernatants removed. Pellets were washed twice in $0.85 \%$ saline with or without $1 \mathrm{mM}$ drug, as in the original mixtures, and final pellets were resuspended in $0.375 \mathrm{~cm}^{-3} 0.85 \%$ saline. The $\mathrm{pH}$ was adjusted to 2.8 with $0.1 \mathrm{~N} \mathrm{HCl}$, and after $10 \mathrm{~min}$ platelets were pelleted and supernatants recovered and neutralized to $\mathrm{pH} 7$ with $0.01 \mathrm{~N} \mathrm{NaOH}$. Dilutions of the radiolabeled $\mathrm{F}\left(\mathrm{ab}^{\prime}\right)_{2}$ starting material and of the different eluates were electrophoresed, nonreduced, on a 7\% SDS-polyacrylamide gel, which was subsequently stained with Coomassie Brilliant Blue, soaked in autofluor (National Diagnostics, Inc., Somerville, NJ), dried, and autoradiographed. Several nonradioactive IgG fragment preparations and commercial molecular weight standards (Bio-Rad Laboratories, Richmond, CA) were included on the gel for reference purposes.

\section{Results}

Binding of dd-IgG and dd fragments to platelet membranes. Fig. 3 shows the dose-dependent response of dd-IgG binding to washed platelet membranes using purified total serum IgG from three different patients, one having quinine-dependent purpura, a second having quinidine-dependent purpura, and a third who showed sensitivity to both drugs. The amounts of purified IgG available limited evaluation to the values shown, which suggests, but may not assure, saturation in each case.

When IgG and its fragments were incubated with platelet membranes, binding occurred with IgG, Fab, and $F\left(a b^{\prime}\right)_{2}$ only in the presence of the drug. Using equimolar amounts of IgG and its fragments, the amounts of each preparation that were eluted after binding to a standard sample of platelet membrane are shown in Fig. $4 a$. IgG showed the maximum, $\mathrm{F}\left(\mathrm{ab}^{\prime}\right)_{2}$ intermediate, and Fab the least binding. In contrast, binding of the Fc fragment was not dd, since the same amount bound whether or not the appropriate drug was present, as shown in Fig. $4 b$.

Competitive inhibition of dd-125I-labeled IgG binding to platelet membranes. To determine whether $\mathrm{F}\left(\mathrm{ab}^{\prime}\right)_{2}, \mathrm{Fab}$, or Fc fragments prepared from dd-IgG bound to the same membrane site as dd-IgG, and to confirm the direct binding measurements, each fragment was tested as a competitor for radiolabeled purified dd-IgG using purified platelet membranes as a solid-phase re-

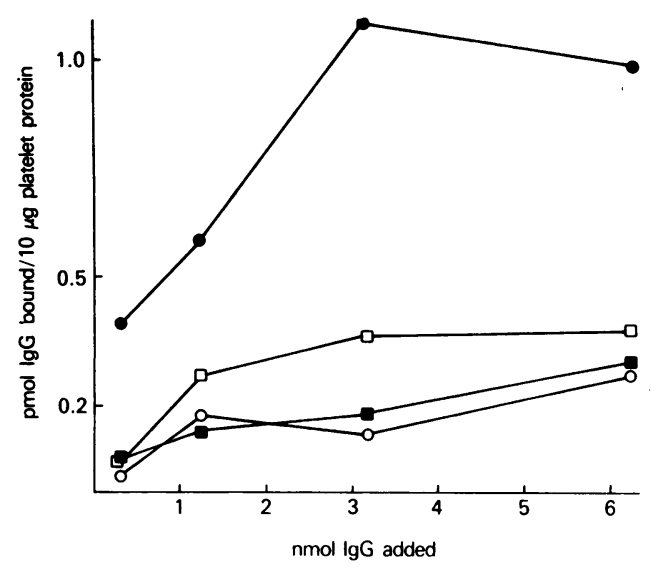

Figure 3. dd binding of purified IgG preparations to platelet membranes. Aliquots of purified IgG from serum of three patients having quinine or quinidine purpura were incubated with platelet membranes in the presence or absence of the appropriate drug. The IgG bound was determined by RIA of an acid elution obtained after a 1-h incubation. Values for each point are the average of triplicates from which background obtained with no drug, or the inappropriate drug was subtracted. Among triplicates the maximum deviation was $10 \%$ of the mean. In the absence of added IgG, the levels of platelet membranebound IgG were $\sim 0.01$ pmol per $10 \mu \mathrm{g}$ of platelet membrane protein. This equals $0.1 \mathrm{fg}$ per platelet equivalent, which is 10 - to 20 -fold lower than the amount of IgG associated with normal, washed, intact platelets assayed by the same technique. With the addition of IgG and no drug or the inappropriate drug, the value of adsorbed IgG was always $<10 \%$ of that when the appropriate drug was present. IgG from patient I (open squares) was used with $1.0 \mathrm{mM}$ quinine, from patient II (solid squares) with $1.0 \mathrm{mM}$ quinidine, and from patient III (solid circles) with $1.0 \mathrm{mM}$ quinidine, (open circles) $1.0 \mathrm{mM}$ quinine. 


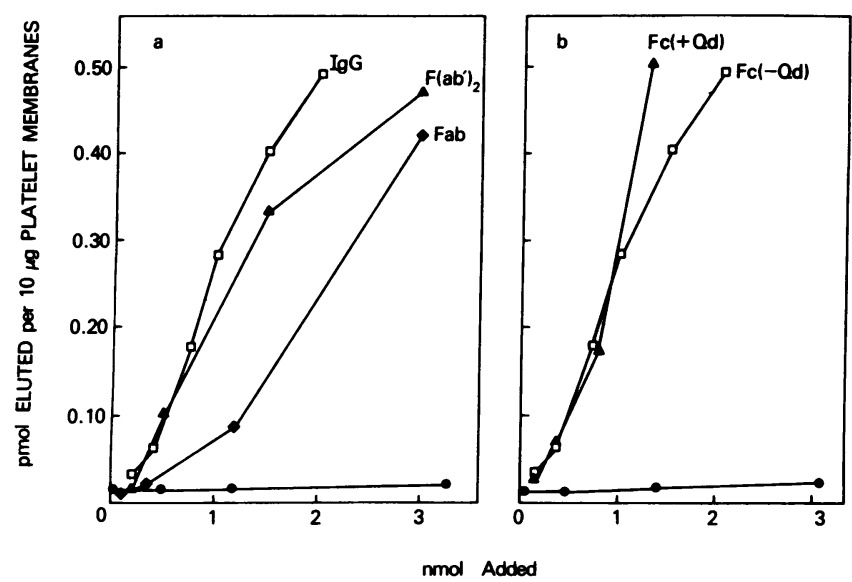

Figure 4. dd binding of purified IgG fragments to platelet membranes. Aliquots of IgG and fragments from patient II were incubated with platelet membranes as described in Fig. 3. $a$ shows the quinidine-dependent binding of the patient's IgG (open squares), $\mathrm{F}\left(\mathrm{ab}^{\prime}\right)_{2}$ (triangles), and Fab (solid squares), and control IgG (solid circles), in the presence of $1.0 \mathrm{mM}$ quinidine after subtraction of background levels of binding of each component in the absence of drug. Binding without drug was in no case $>10 \%$ of the plotted value. $b$ shows the binding of papainprepared $\mathrm{Fc}$ fragment from the same patient without drug (squares) and in the presence of $1.0 \mathrm{mM}$ quinidine (triangles).

ceptor. As shown in Fig. 5, Fab and $F\left(a b^{\prime}\right)_{2}$ fragments and IgG competitively inhibited binding of ${ }^{125} \mathrm{I}-\mathrm{dd}-\mathrm{IgG}$. The difference between $F a b$ and the $F\left(a b^{\prime}\right)_{2}$ with respect to their effectiveness in displacing ${ }^{125} \mathrm{I}$-IgG was consistent with affinity differences expected for monovalent and divalent binding (28). The $\mathrm{Fc}$ fragment caused no binding inhibition. Commercially obtained control Fab, $\mathrm{F}\left(\mathrm{ab}^{\prime}\right)_{2}$, and intact IgG (Kirkegaard \& Perry) also did not significantly inhibit binding of radiolabeled dd-IgG.

Inhibition of dd-IgG-mediated complement fixation. The ability of $F a b$ and $F\left(a b^{\prime}\right)_{2}$ fragments to interact with the dd-IgG binding sites was also observed using complement fixation as the measure of IgG binding. As shown in Fig. 6, both $F\left(a b^{\prime}\right)_{2}$ and Fab significantly inhibited complement fixation by the parent IgG. A summary of the relative efficiency of inhibition of these IgGs by their respective fragments is shown in Table $I$. The molar excess of fragments required to produce $50 \%$ inhibition of maximum complement fixation by IgG, from which

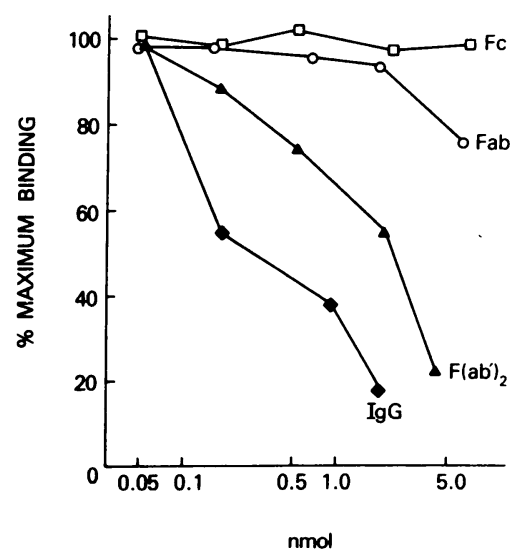

Figure 5. Inhibition of binding of purified radiolabeled dd-IgG to platelet membranes by preparations of IgG and IgG fragments from patient III. Incubations consisted of a standard mixture of ${ }^{125} \mathrm{I}-\mathrm{dd}-\mathrm{IgG}$ plus platelets, to which was added varying amounts of the same unlabeled dd-IgG or $\mathrm{F}\left(\mathrm{ab}^{\prime}\right)_{2}$, Fab, or Fc made from it. All reactions were performed in 1.0 $\mathrm{mM}$ quinidine. Normal IgG and its $\mathrm{F}\left(\mathrm{ab}^{\prime}\right)_{2}$ or Fab fragment, used in parallel experiments, had no effect on the binding of dd-IgG.

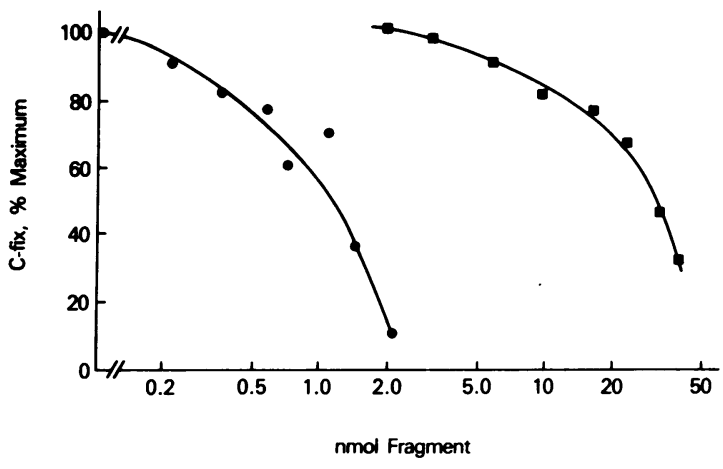

Figure 6. Inhibition of dd-IgG-mediated complement fixation by its respective $F a b$ and $F\left(a b^{\prime}\right)_{2}$ fragments. Complement fixation by the intact IgG from patient II was inhibited by both its Fab (squares) and $\mathrm{F}\left(\mathrm{ab}^{\prime}\right)_{2}$ (circles) fragments. dd complement fixation with intact platelets was performed in the presence of $0.42 \mathrm{nmol} \mathrm{IgG} \mathrm{and} 0.75 \mathrm{mM}$ quinidine. This system fixed $4.8 \mathrm{U}$ of complement. Note that the abscissa, representing nanomoles of fragment, is a logarithmic scale.

they were derived, is 1.6-3-fold for the $\mathrm{F}\left(\mathrm{ab}^{\prime}\right)_{2}$ fragments and 44-75-fold for the Fab fragments.

$S D S-P A G E$ of eluted radiolabeled $d d-F\left(a b^{\prime}\right)_{2}$. Eluates of platelet membranes exposed to $F\left(a b^{\prime}\right)_{2}$ in the presence or absence of drug were electropheresed and autoradiographed as described in Methods.

As shown in Fig. 7, the eluate prepared with quinidine (Fig. 7 , lanes 7 and 8) contained a high concentration of $F\left(a^{\prime}\right)_{2}$, while the eluate prepared without drug (Fig. 7, lane 9) had only barely detectable $\mathrm{F}\left(\mathrm{ab}^{\prime}\right)_{2}$. The dd eluate also contained traces of material of $\sim 50,000 \mathrm{~mol}$ wt that contaminated the $\mathrm{F}\left(\mathrm{ab}^{\prime}\right)_{2}$ preparation (Fig. 7, lanes 5 and 6 ). This contaminant is most likely Fab' fragment derived from the pepsin treatment of IgG that was not removed by the $S$. aureus protein A and anti-Fc columns. The contaminant was relatively low in concentration, as can be seen by its disappearance with dilution.

\section{Discussion}

In an attempt to resolve the conflicting data concerning antibody domain involved in dd-antibody binding, our studies were done

Table I. Inhibition of dd-IgG-mediated Complement Fixation by $F\left(a b^{\prime}\right)_{2}$ and Fab Fragments

\begin{tabular}{|c|c|c|c|c|c|}
\hline & \multirow[b]{3}{*}{ dd-IgG } & \multicolumn{4}{|c|}{$50 \%$ complement fixation inhibition by: } \\
\hline & & \multicolumn{2}{|l|}{$\mathrm{F}\left(\mathrm{ab}^{\prime}\right)_{2}$} & \multicolumn{2}{|l|}{ Fab } \\
\hline & & & $\begin{array}{l}\text { Molar ratio } \\
\text { to } \lg G\end{array}$ & & $\begin{array}{l}\text { Molar ratio } \\
\text { to IgG }\end{array}$ \\
\hline & nmol & nmol & & nmol & \\
\hline Patient I & 0.46 & 0.87 & 1.9 & $>20$ & $>44$ \\
\hline Patient II & 0.42 & 1.24 & 3.0 & 31.6 & 75 \\
\hline Patient III & 0.35 & 0.55 & 1.6 & 19 & 54 \\
\hline
\end{tabular}

Competitive complement fixation experiments were performed with dd-IgG and its $F\left(a b^{\prime}\right)_{2}$ and Fab fragments from three different patients, as described in Methods, and as shown for patient II in Fig. 6. Molar quantities of reagents were calculated on the basis of the following molecular weights: IgG, 160,000; $F\left(a^{\prime}\right)_{2}, 100,000$; and Fab, 50,000. 


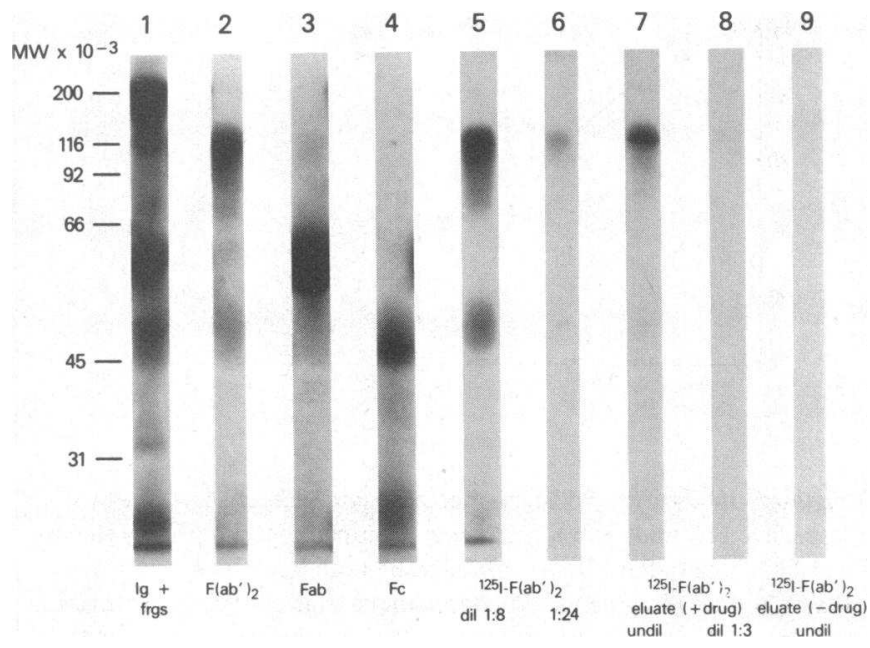

Figure 7. SDS-PAGE of acid elutions of platelet-bound ${ }^{125}$ I-labeled $\mathrm{F}\left(\mathrm{ab}^{\prime}\right)_{2}$, as described in Methods. Reference lanes 1 through 4 contain nonradiolabeled reagents prepared from patient III and visualized by Coomasie Stain. Lane 1 contains IgG and its fragments; lane 2, $\mathrm{F}\left(\mathrm{ab}^{\prime}\right)_{2}$; lane 3, Fab; lane 4, Fc. Lanes 5 to 9 represent autoradiographs from the identical gel. Lane 5 contains ${ }^{125} \mathrm{I}-\mathrm{dd}-\mathrm{F}\left(\mathrm{ab}^{\prime}\right)_{2}$ starting material, diluted 1:8; lane 6, ${ }^{125} \mathrm{I}-\mathrm{dd}-\mathrm{F}\left(\mathrm{ab}^{\prime}\right)_{2}$ diluted 1:24. Lane 7 is undiluted eluate prepared with ${ }^{125} \mathrm{I}-\mathrm{F}\left(\mathrm{ab}^{\prime}\right)_{2}$ in presence of drug; lane 8 , as in lane 7, but diluted 1:3. Lane 9 contains undiluted eluate prepared without quinidine. Molecular weight markers are shown at the left.

using highly purified IgG, IgG fragments, and platelet membranes in four experimental systems. Direct quantitative binding of dd-F( $\left(\mathrm{ab}^{\prime}\right)_{2}$, dd-Fab, and dd-Fc fragments relative to intact ddIgG was measured; two methods of determining inhibition of IgG binding by dd-IgG fragments were used; and membranebound ${ }^{125} \mathrm{I}-\mathrm{dd}-\mathrm{F}\left(\mathrm{ab}^{\prime}\right)_{2}$ was evaluated by qualitative SDS-PAGE. Results of these assays consistently demonstrated that only the Fab domain of the IgG is responsible for dd-IgG binding, and that the affinity of dd binding increases in the order of Fab, $\mathrm{F}\left(\mathrm{ab}^{\prime}\right)_{2}$, and IgG. Additionally, the observed differences in apparent affinity of the monomeric and dimeric fragments, as evaluated by differences in their ability to compete for dd-IgG binding strongly suggest that the Fab-mediated binding of ddIgG to the platelet surface is divalent at the optimal drug concentrations used.

As shown in Fig. 5, an eightfold molar excess of $\mathrm{F}\left(\mathrm{ab}^{\prime}\right)_{2}$ over that of unlabeled dd-IgG was required to inhibit $50 \%$ of the binding of radiolabeled dd-IgG in direct binding experiments, and $\sim 50$-fold $M$ excess was required for $20 \%$ inhibition by Fab. In complement fixation experiments with the three antibodies evaluated in this study, $50 \%$ inhibition of dd binding by the parent IgG required a 1.6- to 3-fold molar excess of $F\left(a^{\prime}\right)_{2}$ and a 44- to 75-fold excess of Fab. The molar ratio causing inhibition by complement fixation assays may have been lower than that observed by direct measurements because of the apparent requirement of nearest neighbor distribution of IgG to fix complement (2). This requirement may cause a disproportionate decrease in complement fixation relative to the number of molecules of IgG displaced. Fc fragments prepared from dd-IgG did not inhibit complement fixation by the parent dd-IgG even when present in a 100-fold molar excess.

Two possible explanations for the requirement of an excess molar concentration of dd-F $\left(a b^{\prime}\right)_{2}$ to compete with dd-IgG from which it was derived are the following: First, although the Fc portion of dd-IgG is not essential for high affinity binding, we cannot rule out the possibility that its presence contributes to the stability of the antibody (possibly the hinge region), and thereby may increase the stability of the antibody-drug-platelet complex. Also, minor structural changes in the $F\left(a b^{\prime}\right)_{2}$ and $F a b$ fragments inherent in the enzymatic cleavage of parent IgG potentially could affect affinity of the overall reaction.

Although each binding curve in Fig. 3 seems to approach a different asymptotic value of saturation, this may be due to variations in apparent affinity between platelet receptor and the different dd-IgGs. Previous studies using whole serum and intact platelets from several different patients described similar results (4). Our results indicate that the number of dd-IgG molecules bound to the platelet at apparent saturation is $20,000-50,000$, which is similar to the estimated $26,000-33,000$ glycoprotein $I_{b}$ molecules on the platelet surface (29). A recent estimate of platelet receptor sites for dd-antibody binding was 36,000161,000 per platelet (4). The range of values is higher than that obtained in the present study which may, in part, be related to our use of purified platelet membranes rather than whole platelets; i.e., when compared on the basis of protein content, purified membranes may contain only $77 \%$ the number of dd-antibody receptor sites as intact platelets. If the value for bound dd-IgG molecules exceeds GPI $_{b}$ complexes, this would imply that each complex may bind more than one dd antibody or that additional binding sites may exist.

It is not yet known which bimolecular reaction, i.e., that between antibody and drug, or cell and drug, occurs as an initial step or whether a quasi-trimolecular reaction takes place. Quantitation of the binding affinity and stoichiometry of the possible bimolecular reactions is difficult because of the above-cited indication that these reactions are of low relative affinity. Preliminary data on such binding in an erythrocyte dd-antibody system indicates the types of approaches that will be necessary to define the dd-antibody system involving platelets (30).

\section{References}

1. Ackroyd, J. F. 1951. The role of complement in sedormid purpura. Clin. Sci. 10:185-205.

2. Shulman, N. R. 1958. Immunoreactions involving platelets. I. A steric and kinetic model for formation of a complex from a human antibody, quinidine as a haptene, and platelets; and for fixation of complement by the complex. J. Exp. Med. 107:665-690.

3. Shulman, N. R. 1963. Mechanism of blood cell damage by adsorption of antigen-antibody complexes. Immunopathology. Int. Symp., Schwabe \& Co., 3rd, 338-352.

4. Christie, D. J., and R. H. Aster. 1982. Drug-antibody-platelet interaction in quinine- and quinidine-induced thrombocytopenia. J. Clin. Invest. 70:989-998.

5. Shulman, N. R. 1958. Immunoreactions involving platelets. IV. Studies on the pathogenesis of thrombocytopenia in drug purpura using test doses of quinidine in sensitized individuals: their implications in idiopathic thrombocytopenic purpura. J. Exp. Med. 107:711-729.

6. Shulman, N. R. 1964. A mechanism of cell destruction in individuals sensitized to foreign antigens and its implications in auto-immunity. Ann. Intern. Med. 60:506-521.

7. Kunicki, T. J., N. Russell, A. T. Nurden, R. H. Aster, and J. P. Caen. 1981. Further studies of the human platelet receptor for quinineand quinidine-dependent antibodies. J. Immunol. 126:398-402.

8. Rosenfeld, S. I., R. J. Looney, J. P. Leddy, D. C. Phipps, G. N. Abraham, and C. L. Anderson. 1985. Human platelet Fc receptor for immunoglobulin G. J. Clin. Invest. 76:2317-2322. 
9. Cheng, C. M., and J. Hawiger. 1979. Affinity isolation and characterization of immunoglobulin $\mathrm{G} \mathrm{Fc}$ fragment-binding glycoprotein from human blood platelets. J. Biol. Chem. 254:2165-2167.

10. Chong, B. H., M. C. Berndt, J. Koutts, and P. A. Castaldi. 1983. Quinidine-induced thrombocytopenia and leukopenia: demonstration and characterization of distinct antiplatelet and antileukocytic antibodies. Blood. 62:1218-1223.

11. van Leeuwen, E. F., C. P. Engelfreit, and A. E. G. Kr. von dem Borne. 1982. Studies on quinine- and quinidine-dependent antibodies against platelets and their reaction with platelets in the Bernard-Soulier syndrome. Br. J. Haematol. 51:551-560.

12. Lerner, W., R. Caruso, D. Faig, and S. Karpatkin. 1985. Drugdependent and non-drug-dependent antiplatelet antibody in drug-induced immunologic thrombocytopenic purpura. Blood. 66:306-311.

13. Kekomaki, R., A. Rajamaki, and G. Myllyla. 1980. Detection of quinidine-specific antibodies with platelet ${ }^{125} \mathrm{I}$-labeled Staphylococcal protein A test. Vox Sang. 38:12-18.

14. Christie, D. J., P. C. Mullen, and R. H. Aster. 1985. Fab-mediated binding of drug-dependent antibodies to platelets in quinidine- and quinine-induced thrombocytopenia. J. Clin. Invest. 75:310-314.

15. Crabtree, G. R. 1980. Fc receptors of a human promyelocytic leukemic cell line: evidence for two types of receptors defined by binding of the Staphylococcal protein A-IgG1 Complex. J. Immunol. 125:448453.

16. Laemmli, U. K. 1970. Cleavage of structural proteins during the assembly of the head of bacteriophage T4. Nature (Lond.). 227:680-685.

17. Bio-Rad Silver Stain. 1984. Bulletin. 1089:1-4.

18. Mage, M. G. 1980. Preparation of Fab fragments from IgG's of different animal species. Methods Enzymol. 70:142-150.

19. Stanworth, D. R., and M. W. Turner. 1978. Immunochemical analysis of immunoglobulins and their sub-units. In Handbook of Experimental Immunology. 3rd ed. D. M. Weir, editor. Blackwell Scientific Publications, London. 6.19-6.21.

20. Barber, A. J., and G. A. Jamieson. 1970. Isolation and characterization of plasma membranes from human blood platelets. J. Biol. Chem. 245:6357-6365.
21. Peterson, G. L. 1983. Determination of total protein. Methods Enzymol. 91:95-119.

22. Smith, M. E., A. J. Hotchkiss, C. A. Leissinger, J. V. Jordan, C. A. Kautz, and N. R. Shulman. 1983. A sensitive immunoprecipitation assay for measuring specific antibodies that cause isoimmune neonatal thrombocytopenia and post-transfusion purpura. Blood. 62(Suppl. 1): 248a. (Abstr.)

23. Newman, P. J., M. A. Knipp, and R. A. Kahn. 1982. Extraction and identification of human platelet integral membrane proteins using Triton X-114. Thromb. Res. 27:221-224.

24. Newman, P. J., and R. A. Kahn. 1983. Purification of human platelet membrane glycoproteins $11 \mathrm{~b}$ and $111 \mathrm{a}$ using high-performance liquid chromatography gel filtration. Anal. Biochem. 132:215-218.

25. Assoian, R. K., N. E. Thomas, E. T. Kaiser, and H. S. Tager. 1982. [ Leu $\left.^{\mathrm{B24}}\right]$ insulin and $\left[\mathrm{Ala}^{\mathrm{B24}}\right]$ insulin: altered structures and cellular processing of B24- substituted insulin ánalogs. Proc. Natl. Acad. Sci. USA. 79:5147-5151.

26. Hotchkiss, A. J., C. A. Leissinger, M. E. Smith, J. V. Jordan, C. A. Kautz, and N. R. Shulman. 1986. Evaluation by quantitative acid elution and radioimmunoassay of multiple classes of immunoglobulin and serum albumin associated with platelets in idiopathic thrombocytopenic purpura. Blood. 67:1126-1131.

27. Shulman, N. R., V. J. Marder, M. C. Hiller, and E. M. Collier. 1964. Platelet and leukocyte isoantigens and their antibodies: serologic, physiologic and clinical studies. Prog. Hematol. 4:222-304.

28. Hornick, C. L., and F. Karush. 1972. Antibodý affinity. III. The role of multivalence. Immunochemistry. 9:325-340.

29. Coller, B. S., E. I. Peerschke, L. E. Scudder, and C. A. Sullivan. 1983. Studies with a murine monoclonal antibody that abolishes ristocetin-induced binding of von Willebrand Factor to platelets: additional evidence in support of GPIb as a platelet receptor for von Willebrand Factor. Blood. 61:99-110.

30. Jordan, J. V., C. E. Jones, M. E. Smith, D. M. Reid, C. A. Kautz, and N. R. Shulman. 1985. Equilibrium dialysis studies of the nature of antibody, drug and cell membrane interaction in drug hemolytic anemia. Blood. 66(Suppl. 1):104a. (Abstr.) 